Journal of Clinical Investigation

Vol. 41, No. 1, 1962

\title{
THE ROLE OF THE HUMAN PLACENTA IN THE TRANSFER AND METABOLISM OF INSULIN *
}

By MARIA G. BUSE, WALTER J. ROBERTS $\dagger$ AND JOHN BUSE

(From the Departments of Biochemistry and Medicine, Medical College of South Carolina, Charleston, S. C.)

(Submitted for publication May 22, 1961 ; accepted September 21, 1961)

Since 1911 the problem of placental permeability to insulin has been studied sporadically. Carlson, Drennan, Orr and Jones $(1,2)$ observed that pregnant dogs failed to develop glycosuria after pancreatectomy and concluded that the fetus protected the mother against diabetes, presumably by diaplacental movement of some substance. Other investigators $(3,4)$, however, were unable to confirm these early studies. Results of work with goats $(5)$, rabbits $(6,7)$ and mice (8) were variable and suggest that species differences exist in the placental permeability to insulin. By in vitro techniques, systems for the proteolytic inactivation of insulin have been demonstrated in the rat (9) and human placenta (10).

This study was undertaken to investigate the role of the human placenta in the transfer and metabolism of insulin in vivo. It was assumed that the placenta handles insulin- $\mathrm{I}^{131}$ as it would unlabeled insulin.

\section{METHOD}

Twenty-eight term-pregnant women, 14 to 41 years old, were chosen for this study without regard to parity. No diabetic patients were included. Except for two patients with mild pre-eclampsia (experiments 3 and 7), no complicating diseases were present. Four patients were delivered by elective repeat cesarean section (experiments $3,7,15,16)$; the remainder had uncomplicated vaginal deliveries.

Sterile solutions of crystalline beef insulin assaying $25 \mathrm{U}$ per $\mathrm{mg}$, labeled with $\mathrm{I}^{131}$; $\mathrm{NaI}^{131}$; and $\mathrm{I}^{131}$-labeled human serum albumin (RISA) were obtained from Abbott Laboratories. Insulin- $\mathrm{I}^{131}$ and RISA were stored

* Presented in part at the meeting of the Southern Section of the American Federation for Clinical Research January 1961, New Orleans, La., and at the Fourth Congress of the International Diabetes Federation, July 1961, Geneva, Switzerland. This investigation was supported by Grants A-2001(C2-3) and 2A-5078(C3-4), National Institute of Arthritis and Metabolic Diseases.

$\dagger$ Fellow in Diabetes and Endocrinology, National Institute of Arthritis and Metabolic Diseases. undiluted at $4^{\circ} \mathrm{C}$. Insulin- $\mathrm{I}^{131}$ was used within 7 days of its preparation by the manufacturer. The specific activity of insulin- $\mathrm{I}^{131}$ was approximately $6 \mathrm{mc}$ per $\mathrm{mg}$ on arrival. At the time of administration it was 95 to 98 per cent precipitable with trichloroacetic acid (TCA) in the presence of $5 \mathrm{mg}$ per $\mathrm{ml}$ added human serum albumin. When required, the radioactive materials were diluted with sterile saline prior to injection, to bring them to $20 \mu \mathrm{c}$ per $\mathrm{ml}$. After delivery in aqueous solution by syringe, insulin- $\mathrm{I}^{131}$ was 93 to 97 per cent precipitable with TCA due to losses of protein-bound radioactivity by adsorption to glass $(10,11)$. In subsequent experiments glass adsorption was minimized by using saline containing 0.5 per cent human serum albumin for the dilution of the labeled insulin.

Several preparations of insulin- $\mathrm{I}^{131}$ were analyzed by unidimensional descending chromatography on Munktell 20/150 filter paper (12) in butanol-acetic acid-water (3: $1: 4$ or $8.5: 1: 7.5)$ after being supplemented with unlabeled carrier insulin, sodium iodide, L-monoiodotyrosine (MIT) and L-diodotyrosine (DIT). The iodinated carrier compounds were localized by staining with a solution of ceric sulfate-arsenious acid followed by aniline in acetone (13). Duplicate chromatograms were also sprayed with 0.1 per cent ninhydrin in acetone. The papers were cut into $1-$ to $2-\mathrm{cm}$ segments and counted in a scintillation well counter. When detectable, the sum of the radioactivity migrating with the mobility of MIT and DIT was less than 1 per cent of the total radioactivity.

Three preparations of insulin- $\mathrm{I}^{131}$ were analyzed for homogeneity by hydrodynamic-flow paper chromatography (14) and by electrophoresis on Whatman no. 3 filter paper, in barbituric acid-sodium barbiturate buffer, $\mathrm{pH}$ 8.6 , ionic strength 0.075 , duration 16 hours. The tests were repeated at $4^{\circ} \mathrm{C}$, after varying time intervals of storage not exceeding 6 days. Immediately prior to electrophoresis the stock insulin- $\mathrm{I}^{131}$ solution was diluted with human serum. After staining with bromphenol blue the paper strips were cut into $0.5-$ to $1-\mathrm{cm}$ segments and counted in a scintillation well counter. As judged by published criteria (14), products of radiation damage or spontaneous degradation did not exceed 5 per cent of the total radioactivity.

At least 1 hour prior to delivery the patients were premedicated with 15 drops of saturated solution of potassium iodide to prevent the uptake of $\mathrm{I}^{131}$ by the thyroid.

Each of 24 patients received a single i.v. injection of either $0.5 \mathrm{U}$ of insulin- $\mathrm{I}^{131}$ (15 patients), $\mathrm{NaI}^{131}$ ( $7 \mathrm{pa}$ tients), or RISA ( 2 patients) 7 to 274 minutes prior to 
delivery. The administered doses of radioactivity ranged from 40 to $100 \mu \mathrm{c}$. Four additional patients received 60 to $90 \mu \mathrm{c}$ of insulin- $\mathrm{I}^{131}$ infused by slow i.v. drip in $500 \mathrm{ml}$ saline, at as constant a speed as possible to deliver the total dose of insulin at or just before the time of delivery.

At delivery, blood was obtained simultaneously from the umbilical vein and from an antecubital vein of the mother and placed in heparinized tubes. Immediately upon delivery the placenta was washed free of blood clots and frozen on dry ice.

Blood was quickly centrifuged and 2-ml aliquots of plasma counted in a scintillation well counter. Plasma proteins were precipitated with 2 vol of 20 per cent TCA, and $2-\mathrm{ml}$ aliquots of the supernatant were counted. The precipitates were washed three times with normal saline and counted. All counting was carried out on duplicate samples, and sufficient counts were obtained to reduce the probable error of the measurement to less than \pm 2 per cent. The TCA-soluble radioactivity contained per milliliter of plasma was calculated by the dilution principle (assumed that plasma contains 93 per cent water). Recoveries (TCA-precipitable + TCA-soluble counts as per cent of total counts) ranged from 86 to 109 per cent (mean, 96).

All plasma samples were precipitated with TCA within 25 minutes after collecting blood. To exclude the possibility that degradation of insulin- $\mathrm{I}^{131}$ occurred in vitro, the following experiments were carried out. Maternal venous blood and umbilical vein blood were obtained at delivery from two patients who had not received radioactive medication. Plasma was immediately separated by centrifugation. Insulin- $\mathrm{I}^{131}$ was diluted with 0.5 per cent human serum albumin and $0.1 \mathrm{ml}$ of this solution added to $8 \mathrm{ml}$ of maternal and fetal plasma. Duplicate samples of each plasma (containing $3 \times 10^{-3} \mu \mathrm{g}$ of insulin$\mathrm{I}^{131}$ per $\mathrm{ml}$ ) were either precipitated immediately with 2 vol TCA; left standing at room temperature for 1 hour prior to TCA precipitation; or incubated at $37^{\circ} \mathrm{C}$ with shaking for 1 hour, prior to precipitation with TCA. The precipitable and soluble fractions were processed as described earlier and counted in a scintillation well counter. Insulin- $\mathrm{I}^{131}$ was 96 per cent precipitable with TCA immediately after its in vitro addition to maternal or fetal plasma and after the samples had stood for 60 minutes at room temperature. After 1-hour incubation at $37^{\circ} \mathrm{C}$ the TCA-precipitable radioactivity decreased by 1.5 to 3 per cent in different experiments. There was no difference between maternal and umbilical vein plasma in their capacity to degrade insulin. This confirms reports of "negligible insulinase activity" in maternal and cord blood at delivery (10).

Frozen placentas were cut with a sharp knife into 2- to 3-mm thick slices and the chorionic plate trimmed away. Slices weighing approximately $2 \mathrm{~g}$ each were weighed to the nearest $0.1 \mathrm{mg}$, placed in Wasserman tubes and counted in the scintillation well counter. Counts thus obtained were reproducible and not appreciably influenced by geometry. Results were expressed as counts per minute per gram wet weight.

Washing. The slices were washed at $0^{\circ} \mathrm{C}$ in $20 \mathrm{ml}$ of balanced salt solution (bicarbonate buffer) (15) containing $300 \mathrm{mg}$ glucose per $100 \mathrm{ml}$ on a rotating shaker in an atmosphere of 95 per cent $\mathrm{O}_{2}$ and 5 per cent $\mathrm{CO}_{2}$. Washings were carried out for periods of up to 1 hour in three changes of buffer containing glucose. Incubation of tissue slices was done in a Dubnoff metabolic shaker at $37^{\circ}$ to $38^{\circ} \mathrm{C}$ in the same medium and atmosphere. At timed intervals the slices were removed, blotted, reweighed, and counted. Dry weight was obtained by drying in an oven for 3 hours at $105^{\circ} \mathrm{C}$.

Placental homogenates. Thawing placental slices were homogenized with bicarbonate buffer (15) containing 300 $\mathrm{mg}$ glucose per $100 \mathrm{ml}(1: 1 \mathrm{wt} / \mathrm{vol})$ in a ground-glass tissue homogenizer maintained at $4^{\circ} \mathrm{C}$. The homogenate was allowed to sediment in the cold for 5 to 10 minutes, then 1- or 2-ml aliquots of the supernatant were placed in iced Wasserman tubes, corked, and gassed through a needle for 5 minutes with 95 per cent $\mathrm{O}_{2}$ and 5 per cent $\mathrm{CO}_{2}$. The tubes were sealed with paraffin and incubated with shaking in a water bath at $37^{\circ}$ to $38^{\circ} \mathrm{C}$ or at $0^{\circ} \mathrm{C}$. At timed intervals paired tubes were removed from the incubator, placed in an ice-water bath and immediately precipitated with one or two parts of 20 per cent TCA. The precipitable and nonprecipitable fractions were processed as described for plasma and counted in a scintillation well counter.

Presentation of data. The radioactivity contained per milliliter plasma or gram placenta is expressed as counts per minute. With the counting equipment used, $1 \mu \mathrm{c}$ of $\mathrm{I}^{131}$ registers $1.0 \times 10^{6} \mathrm{cpm}$ over a background of $250 \mathrm{cpm}$. Means are indicated \pm the standard errors. The $t$ test of significance was carried out according to Fisher and Gates (16). Experiment numbers are indicated in all tables and figures to allow correlation of different parameters of the same experiment.

\section{RESULTS}

\section{Plasma studies}

Table I shows the radioactive counts found in maternal and fetal plasma at varying time intervals after single i.v. injections or infusions of insulin$\mathrm{I}^{131}$ in 19 patients, and after single i.v. injections of $\mathrm{NaI}^{131}$ in 7 patients. It will be observed that after the administration of insulin- $\mathrm{I}^{131}$, counts appeared in both the TCA-precipitable and TCA-soluble fractions of maternal plasma. The TCAsoluble counts increased with time in maternal plasma owing to the progressive degradation of the labeled insulin $(14,17)$.

The TCA-precipitable counts in cord plasma after insulin- $\mathrm{I}^{131}$ were consistently low. Counts of similar magnitude were found in the fetal TCA precipitates after the injection of $\mathrm{NaI}^{131}$. The mean $\pm \mathrm{SE}$ of the TCA-precipitable counts in fetal plasma after the injection or infusion of in- 
TABLE I

Radioactive counts in maternal and cord plasma at delivery after intravenous administration of 40 to $100 \mu \mathrm{c}$ of insulin-I $I^{131}$ or $\mathrm{Na} I^{131}$ to the mother

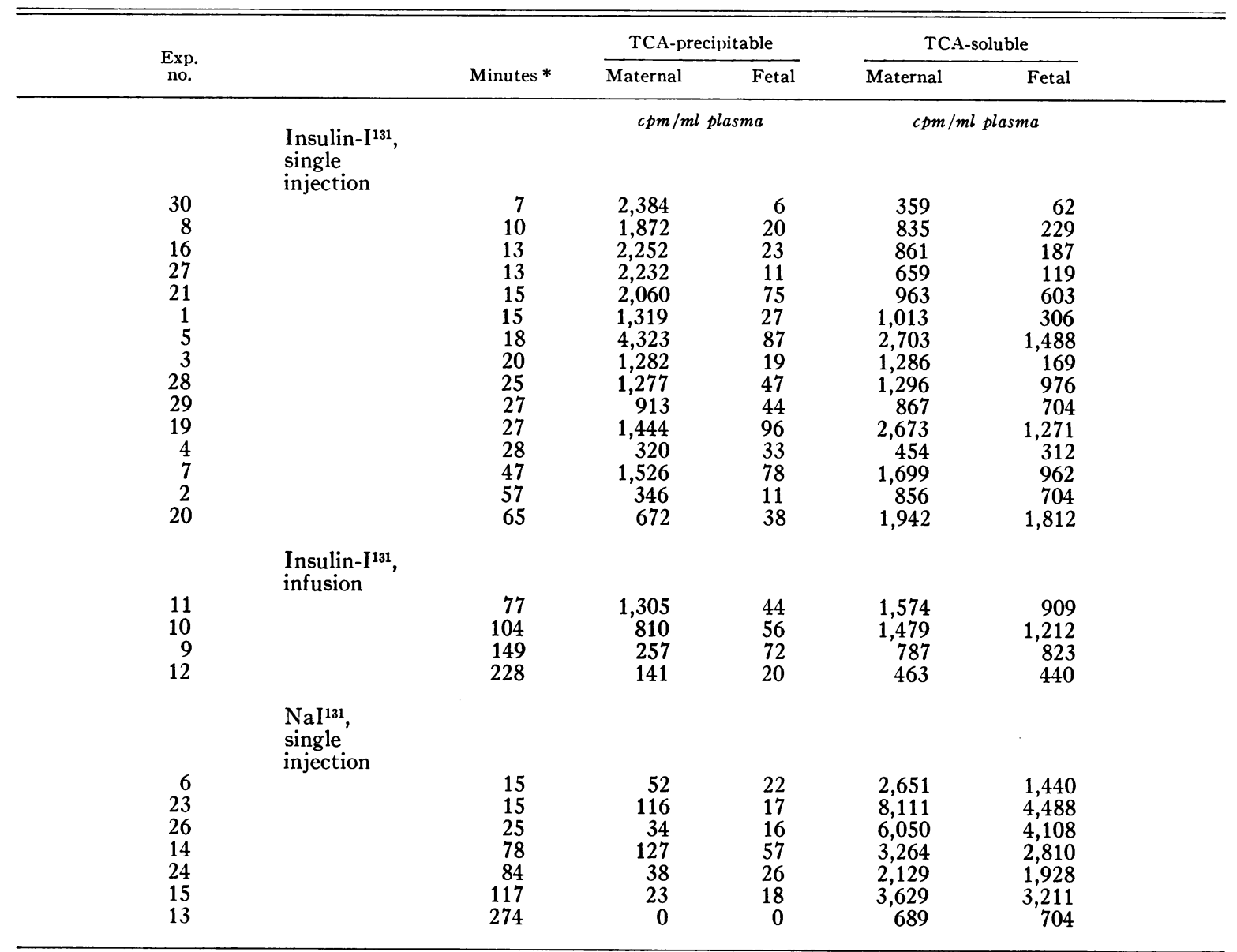

${ }^{*}$ Minutes $=$ time after single i.v. injection or from start of continuous infusion.

sulin- $\mathrm{I}^{131}$ was $42 \pm 6.3 \mathrm{cpm}$, while after $\mathrm{NaI}^{131}$ it was $22 \pm 6.9 \mathrm{cpm}$. This difference is of doubtful significance $(0.1>p>0.05)$. However, when the fetal TCA-precipitable radioactivity was expressed as a function of the TCA-soluble counts present in cord plasma, it was found that $0.8 \pm$ 0.30 per cent of the TCA-soluble radioactivity was trapped in the fetal precipitate after the injection of $\mathrm{NaI}^{131}$, while $8.4 \pm 1.05$ per cent appeared after the administration of insulin- $\mathrm{I}^{131}$. This difference is significant $(p<0.01)$. If the TCA-precipitable counts in fetal plasma represented in both cases coprecipitation artifacts of inorganic iodide, it would be anticipated that the ratio of soluble to precipitable counts would be similar. Thus, the present experiments do not exclude the possibility that small amounts of insulin- $\mathrm{I}^{131}$ or its circulating
TCA-precipitable breakdown products may have crossed the placental barrier during the period of observation. The low levels of TCA-precipitable radioactivity found in fetal blood did not allow further characterization of this material.

Significant counts appeared rapidly in the TCAsoluble fraction of cord plasma after the administration of insulin- $\mathrm{I}^{131}$ or $\mathrm{NaI}^{131}$. The maternal TCA-soluble radioactivity equilibrated with the fetal circulation at approximately the same rate after either substance. This is in agreement with the finding that the main circulating TCA-soluble breakdown product of insulin- $\mathrm{I}^{131}$ in plasma is iodide $^{131}(14,18)$.

Figure 1 illustrates the equilibration of TCAsoluble radioactivity between mother and fetus after the injection of $\mathrm{NaI}^{131}$ or insulin- $\mathrm{I}^{131}$ in $30 \mathrm{pa}$ - 


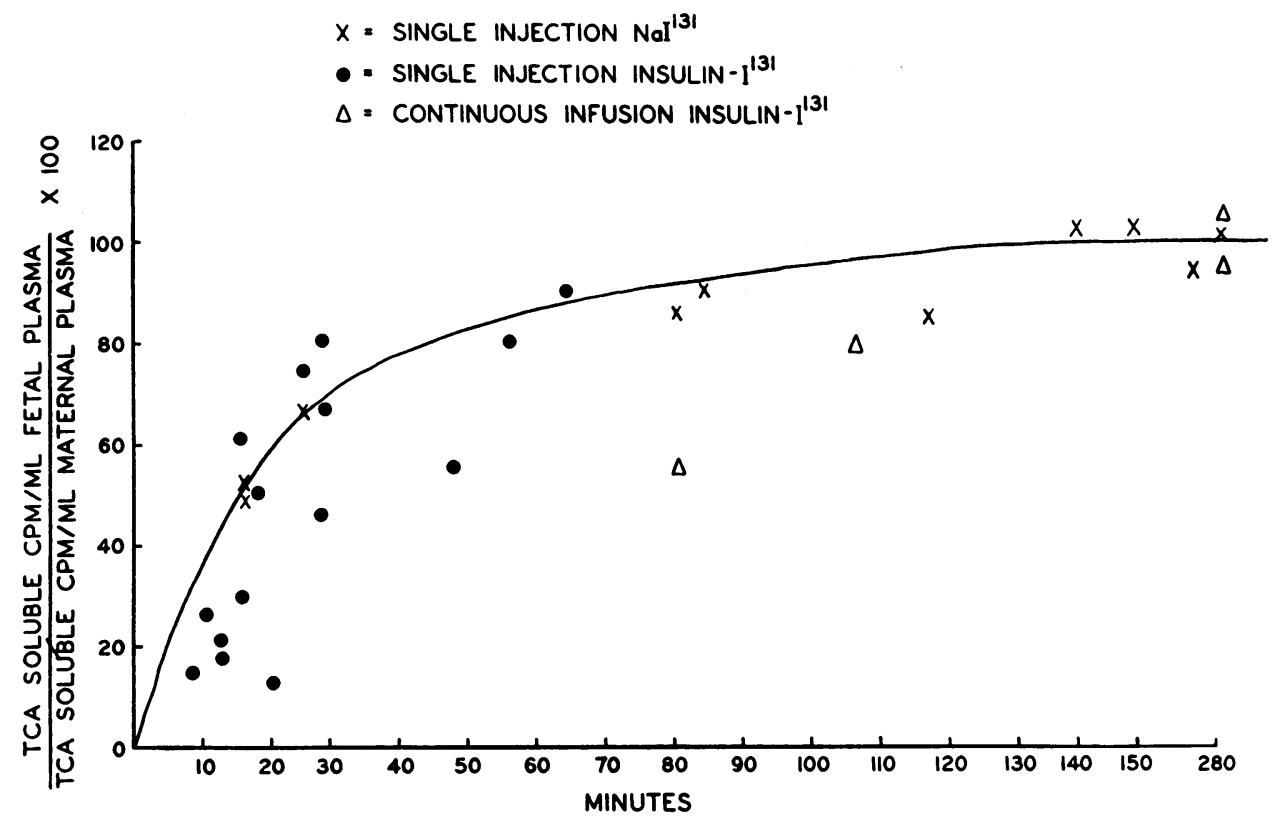

Fig. 1. EQuilibration of TCA-soluble Radioactivity Between maternal and fetal PLASMA AFTER INTRAVENOUS ADMINISTRATION OF NAI ${ }^{131}$ OR INSULIN-I ${ }^{131}$ TO THE MOTHER. Both samples were obtained at delivery. Minutes $=$ time after single injection or from start of continuous infusion.

tients, using the data from Table I. The curved line representing the rate of equilibration of iodide $^{131}$ has been adjusted visually to fit the data of the eight patients who received a single injection of $\mathrm{NaI}^{131}$. It is apparent that equilibration between mother and fetus was approximately 50 per cent at 15 minutes and 90 per cent at 80 minutes after the injection of $\mathrm{NaI}^{131}$. Although there is considerable scatter of the data in the insulin- $\mathrm{I}^{131}$ experiments, it is apparent that the TCA-soluble radioactivity did not appear faster in cord plasma after the injection or infusion of insulin- $\mathrm{I}^{131}$ than after $\mathrm{NaI}^{131}$. The very low levels of TCA-precipitable radioactivity found in fetal plasma after the injection of insulin- $\mathrm{I}^{131}$ to the mother could be interpreted as owing to the rapid degradation of the hormone by the fetus. If significant amounts of insulin- $\mathrm{I}^{131}$ had crossed the placenta rapidly and the rate of fetal insulin degradation greatly exceeded the maternal rate, an accumulation of TCAsoluble radioactivity in cord plasma may have been expected. However, the possibility of slow transplacental passage of insulin, followed by rapid equilibration of the products of fetal degradation, cannot be excluded.

Body scanning of one baby was carried out at birth, 50 minutes after the mother had received $100 \mu \mathrm{c}$ of insulin- $\mathrm{I}^{131}$ i.v. Scanning was performed manually with a heavily shielded scintillation probe with a straight bore collimator (crystal 1 inch, bore $1 \frac{1}{4}$ inch) placed in direct apposition to the skin. Blood arriving via the umbilical artery passes first through the fetal liver. This organ binds 50 per cent of the insulin- $\mathrm{I}^{131}$ contained in a perfusate in a single circulation in rats and human adults (19). Thirty minutes after single peripheral injections of insulin- ${ }^{131}$ to human adults, the liver : thigh ratio on external counting is of the order of 50:1 (14). Therefore, a higher counting rate may be expected over the baby's liver if significant amounts of insulin- $\mathrm{I}^{131}$ had crossed the placental barrier, unless fetal hepatic insulin degradation is much faster than that of adults. Although counts were six times above background, no difference was observed when scanning over the heart, liver, thigh or thyroid gland of the infant. (The thyroid was blocked by premedicating the mother with iodide.)

\section{Placental studies}

a) Radioactive content of placental slices. Table II compares the radioactivity found in placental slices (expressed as counts per gram wet weight) 
TABLE II

Comparison of the concentrations of radioactivity in placenta and maternal plasma after single injections of insulin-I $I^{131}$, NaI $I^{131}$, or RISA*

\begin{tabular}{|c|c|c|c|c|c|c|}
\hline Exp. no. & & $\begin{array}{l}\text { Before } \\
\text { delivery }\end{array}$ & Plasma & $\begin{array}{l}\text { Placenta } \\
\text { (wet wt) }\end{array}$ & $\mathrm{SE}$ & $\frac{\mathrm{cpm} / \mathrm{g} \text { placenta }}{\mathrm{cpm} / \mathrm{ml} \text { plasma }} \times 100$ \\
\hline & Insulin-I 131 & $\min$ & $c p m / m l$ & $\mathrm{cpm} / \mathrm{g}$ & & \\
\hline $\begin{array}{l}30 \\
27 \\
21 \\
28 \dagger \\
19 \\
29 \\
20\end{array}$ & & $\begin{array}{r}7 \\
13 \\
15 \\
25 \\
27 \\
28 \\
65\end{array}$ & $\begin{array}{l}3,099 \\
3,483 \\
3,196 \\
2,966 \\
4,755 \\
1,908 \\
2,944\end{array}$ & $\begin{array}{l}2,355 \\
5,304 \\
6,508 \\
3,756 \\
8.895 \\
3,577 \\
2,630\end{array}$ & $\begin{array}{l} \pm 267[5] \\
\pm 283[16] \\
\pm 168[8] \\
\pm 314[8] \\
\pm 333[2] \\
\pm 97[6] \\
\pm 300[8]\end{array}$ & $\begin{array}{r}75.4 \\
152.3 \\
206.1 \\
126.6 \\
187.1 \\
186.5 \\
89.3\end{array}$ \\
\hline $\begin{array}{l}\text { Mean } \pm S E \\
\text { Mean } \pm S E\end{array}$ & & $\begin{array}{r}7-65 \\
13-28\end{array}$ & & & & $\begin{array}{l}149.4 \pm 22.4 \\
183.0 \pm 11.2\end{array}$ \\
\hline $\begin{array}{l}23 \\
26 \\
24\end{array}$ & $\mathrm{NaI}^{131}$ & $\begin{array}{l}15 \\
25 \\
84\end{array}$ & $\begin{array}{l}8,336 \\
6,321 \\
2,068\end{array}$ & $\begin{array}{l}3,693 \\
2,732 \\
1,070\end{array}$ & $\begin{array}{ll} \pm & 73[8] \\
\pm & 81[12] \\
\pm & 12[12]\end{array}$ & $\begin{array}{l}44.3 \\
43.2 \\
51.7\end{array}$ \\
\hline Mean $\pm \mathrm{SE}$ & & $15-84$ & & & & $46.4 \pm 2.7$ \\
\hline $\begin{array}{l}17 \\
22\end{array}$ & RISA & $\begin{array}{r}8 \\
13\end{array}$ & $\begin{array}{l}32,720 \\
22,170\end{array}$ & $\begin{array}{l}3,792 \\
2,538\end{array}$ & $\begin{array}{l} \pm 149[2] \\
\pm 85[12]\end{array}$ & $\begin{array}{l}11.6 \\
11.4\end{array}$ \\
\hline Mean $\pm \mathrm{SE}$ & & $8-13$ & & & & $11.5 \pm 0.1$ \\
\hline
\end{tabular}

${ }^{*} \mathrm{cpm}=$ Counts per minute $\mathrm{SE}=$ standard error $;[]=$ number of placental slices.

$\dagger$ Placentas were frozen at delivery except in experiment 28 where placenta was transported to the laboratory immersed in iced buffer. This experiment is not included in the mean.

to that contained in maternal plasma (counts per milliliter) at timed intervals after single injections of insulin- $\mathrm{I}^{131}, \mathrm{NaI}^{131}$, or RISA. After the injection of RISA, the concentration of radioactivity per gram placenta was 11.5 per cent of the concentration found per milliliter plasma. Since less than 1 per cent of the maternal plasma radioactivity was found in fetal plasma 8 to 13 minutes after the RISA injection, it is probable that maternal plasma occupies 11.5 per cent of the volume of the placenta.

In three patients who received $\mathrm{NaI}^{131}$, the " $\mathrm{I}^{131}$ space" of the placenta ranged between 44.3 and 51.7 per cent of wet weight 15 to 84 minutes after the injection of $\mathrm{NaI}^{131}$. Since, after 80 minutes the iodide ${ }^{131}$ concentrations in maternal and fetal plasma are practically equal (Table I, Figure 1) and in addition iodide ${ }^{131}$ equilibrates with the water of red blood cells (20), the iodide space of 51.7 per cent represents the fraction of the volume of the placenta occupied by maternal plasma, fetal plasma, 65 per cent of the volume of the red cells, and probably includes the extravascular intercellular space.

In seven patients who received insulin- $\mathrm{I}^{131}$ the ratio of placental counts to maternal plasma counts was significantly higher than after RISA or $\mathrm{NaI}^{131}$ at all time intervals studied. Seven minutes after the injection of insulin- $\mathrm{I}^{131}, 75$ per cent of the total radioactivity contained per milliliter maternal plasma was present per gram placenta. This ratio increased with time to approximately 180 per cent 13 to 28 minutes after the injection of insulin- $\mathrm{I}^{131}$. After 65 minutes the radioactivity in the placenta was 90 per cent of the plasma radioactivity. At this time 75 per cent of the radioactivity in plasma was TCA-soluble, presumably iodide $(14,18)$, which equilibrates with 46 per cent of the placenta. In addition, at least 25 per cent of the TCA-precipitable plasma radioactivity probably consisted of circulating breakdown products of insulin- ${ }^{131}$, which undergo slow systemic degradation (14). As these products reportedly have a much smaller space of distribution than unaltered insulin- $\mathrm{I}^{131}(14,21)$, it is possible that they are less available to the placental tissue than is insulin.

Although complete distribution of insulin- $\mathrm{I}^{131}$ in the apparent insulin space requires 30 to $40 \mathrm{~min}-$ 
utes in humans (14), the above ratios cannot be explained on the basis of falling maternal plasma radioactivity and indicate that the placenta traps insulin- $\mathrm{I}^{131}$. Since erythrocytes do not concentrate insulin- $\mathrm{I}^{131}(17)$, the labeled material must be concentrated by the placental tissue per se.

At each time interval after the injection of insulin- ${ }^{131}$ a significant fraction of maternal plasma radioactivity was TCA-soluble (Table I), representing mainly inorganic iodide ${ }^{131}$ which equilibrates with approximately 46 per cent of the placenta (Table II). Corrected ratios can be calculated as follows: [ (cpm per $\mathrm{g}$ wet wt placenta) (TCA-soluble cpm per $\mathrm{ml}$ maternal plasma $\times$

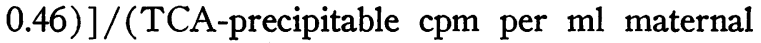
plasma). Seven minutes after the injection of insulin $\mathrm{I}^{131}$ this ratio was 0.9 , and ranged from 2.5 to 3.5 between 13 and 65 minutes after the injection. Thus, if the placenta traps all TCA-precipitable material in plasma without selectivity, a gradient of $3: 1$ between placenta and plasma is rapidly established. The true ratio of placental to plasma insulin may be higher if the placenta selectively binds insulin- $\mathrm{I}^{131}$ and not its TCA-precipitable breakdown products which appear in plasma as a product of systemic insulin degradation (14).
When the radioactivity contained in placental slices was calculated as a percentage of the total radioactivity injected, it was found that 0.3 per cent of the injected radioactivity was present in $100 \mathrm{~g}$ placenta 7 minutes after the injection of insulin- $\mathrm{I}^{131}, 0.7$ to 0.9 per cent between 13 and 28 minutes, and 0.4 per cent after 65 minutes. An average placental weight of $500 \mathrm{~g}$ assumed, 4 per cent of the injected total radioactivity could be recovered in the placenta 13 to 28 minutes after the injection of insulin- ${ }^{131}$.

b) Effect of washing on radioactive content of placental slices. After showing that the placenta "traps" insulin-I ${ }^{131}$, it was of interest to determine whether the placental radioactivity could be removed by prolonged washing. Figure 2 summarizes the results of three typical experiments conducted on placental slices of patients who received single i.v. injections of RISA, insulin- ${ }^{131}$ or $\mathrm{NaI}^{131}$ before delivery. Essentially identical results were obtained in ten similar experiments. The values are expressed as the percentage of the initial counts contained per gram placenta after timed intervals of washing.

It can be observed that after 60 minutes' washing, more than 95 per cent of the initial radio-

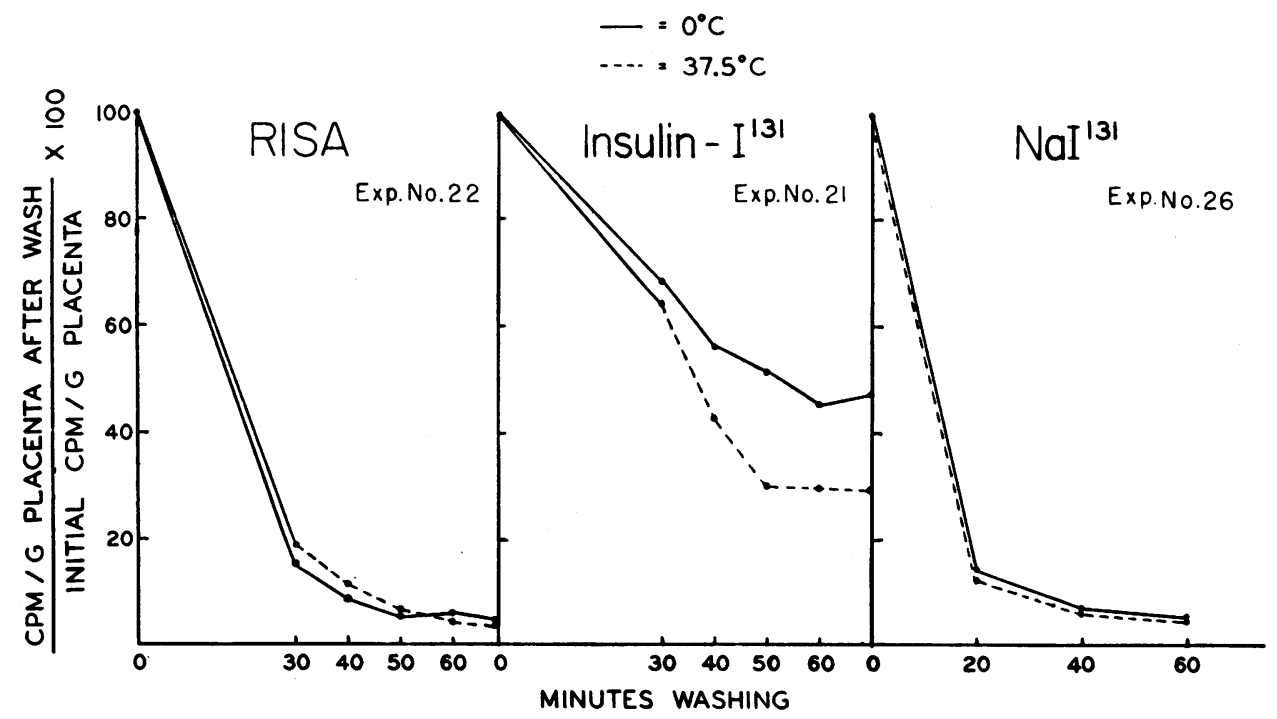

Fig. 2. THE efFect of WASHING ON the RAdioactive CONTENT OF PLACENTAL SLices. RISA, insulin- $\mathrm{I}^{131}$ or $\mathrm{NaI}^{181}$ was injected i.v. prior to delivery. Placentas were frozen on dry ice. Thawing placental slices were weighed and counted prior to washing in $20 \mathrm{ml}$ of bicarbonate buffer (11) containing glucose, $\mathrm{pH} 7.4$, at $0^{\circ}$ or $37.5^{\circ} \mathrm{C}$, with shaking. The buffer was changed every 20 to 30 minutes. At the time intervals indicated the slices were blotted, reweighed and recounted. 


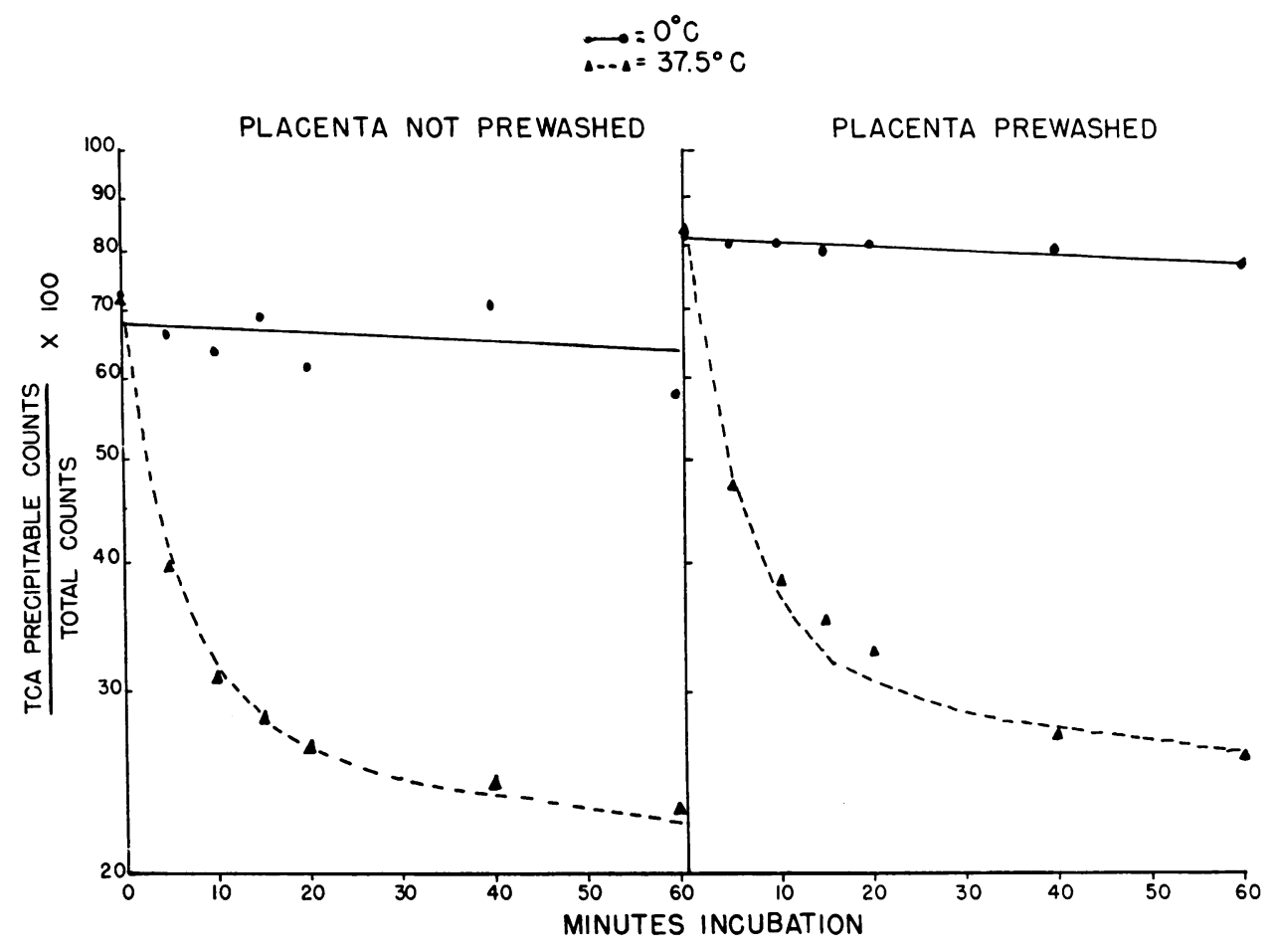

Fig. 3. Degradation of the bound labeled material by placental homogenates after THE INJECTION OF INSULIN- $\mathrm{I}^{131}$. Insulin- $\mathrm{I}^{131}$ was injected 7 minutes prior to delivery. The placenta was frozen on dry ice. Thawing placental slices were homogenized at $4^{\circ} \mathrm{C}$ with an equal volume of bicarbonate buffer (11) containing glucose. "Placenta prewashed" indicates washing of slices for 40 minutes in two changes of iced buffer prior to homogenization. After incubation at $37.5^{\circ}$ or $0^{\circ} \mathrm{C}(\mathrm{pH} 7.4)$ paired samples were precipitated with TCA. The dots indicate the experimental data, the lines the theoretical curves (for calculations see text).

activity was removed from the placental slices of patients who had received RISA or $\mathrm{NaI}^{131}$. There was no significant difference in the efficiency of washing at $0^{\circ}$ or at $37.5^{\circ} \mathrm{C}$. After washing insulin- $\mathrm{I}^{131}$-containing slices for 70 minutes at $0^{\circ} \mathrm{C}$, half of the initial radioactivity remained bound to the tissue. Transferring these slices to a bath at $37.5^{\circ} \mathrm{C}$ significantly decreased the radioactivity that remained bound to the tissue.

Placentas that were frozen on dry ice immediately after delivery were used in the above experiments. In order to exclude the possibility that the firm binding of insulin- $\mathrm{I}^{131}$ to the slices was due to alterations of the cells after freezing and thawing, a similar experiment was performed immediately after delivery on a placenta that was carried from the delivery room to the laboratory in iced buffer. In this case 72 per cent of the initial radioactivity remained bound to the tissue slices after $70 \mathrm{~min}$ utes' washing at $0^{\circ} \mathrm{C}$. c) Placental homogenates. Since after the injection of insulin- $\mathrm{I}^{131}$ more labeled material can be removed from slices of placenta when washing at $37^{\circ}$ than at $0^{\circ} \mathrm{C}$, experiments were carried out to investigate whether this was due to decreased binding at higher temperatures or to degradation of the labeled material by the tissue.

Figure 3 shows that 7 minutes after the injection of insulin- $\mathrm{I}^{131}$ into the mother, the bound hormone is degraded by homogenates of placenta when incubated at $37.5^{\circ} \mathrm{C}$.

The graph illustrates two of four similar experiments. Thawing placental slices were either homogenized at $4^{\circ} \mathrm{C}$ without further manipulations or washed prior to homogenization for 40 minutes in two changes of $20 \mathrm{ml}$ bicarbonate buffer at $0^{\circ} \mathrm{C}$ in order to remove trapped blood.

Aliquots of the homogenates were incubated with shaking at $37.5^{\circ}$ or $0^{\circ} \mathrm{C}$. At the time intervals indicated the reaction was stopped by adding 
cold TCA. Values are expressed as the fraction of the total radioactivity that was precipiated by TCA after timed intervals of incubation.

By inspection, the general shapes of the curve resulting from incubation of placental homogenates with or without prewashing are identical. Since the data obtained with homogenates of prewashed placental slices exclude plasma components, it represents the degradation of the bound labeled material.

When incubated at $0^{\circ} \mathrm{C}$ this degradation proceeded as a slow first-order reaction with an apparent $t_{1}$ of 345 minutes. When incubated at $37.5^{\circ} \mathrm{C}$ the labeled material underwent rapid degradation manifest by a decrease of the TCAprecipitable $\mathrm{I}^{131}$ and an increase of the TCA-soluble counts.

It is not probable that this degradation process conforms to Michaelis-Menten kinetics, owing to the low concentration of substrate. When insulin- $\mathrm{I}^{131}$ is added in vitro to placental extracts $(0.083 \mathrm{~g}$ placenta per $\mathrm{ml})$ the $\mathrm{Km}$ of insulin degradation is $3.8 \times 10^{-\tau}$ moles per L (10). Assumed that all the TCA-precipitable radioactivity trapped in the placenta in the present experiments was insulin- $\mathrm{I}^{131}$, the concentration would be $2.3 \times 10^{-10}$ moles per $\mathrm{kg}$ placenta, or less than one-thousandth of the substrate concentration that gives half the maximal velocity in vitro.

Examination of the concentration changes of the TCA-precipitable material in Figure 3 suggests that both the early and the late changes may be considered as first-order reactions. Freinkel and Goodner demonstrated that placental extracts degrade added insulin- $\mathrm{I}^{131}$ in vitro by proteolysis, giving rise to monoiodotyrosine- and diiodotyrosine-like materials and probably labeled peptides (10). It is probable that some of these intemediary products are TCA-precipitable and that they undergo further degradation (14).

A system representing two simultaneous firstorder degradations, proceeding independently in separate compartments, could not be satisfactorily fitted to the experimental data. The following equation defines a system where the original TCAprecipitable material $\left(P_{o}\right)$ undergoes first-order degradation with the formation of partially TCAprecipitable intermediary products which then undergo further first-order degradation. Thus, the experimentally determined concentrations of TCAprecipitable labeled material $\left(P_{t}\right)$ would represent the remainder of the original material plus a fraction of the intermediary products.

$$
P_{t}=P_{0} e^{-k_{1} t}+\alpha\left[\frac{k_{1}}{k_{2}-k_{1}} P_{0}\left(e^{-k_{1} t}-e^{-k_{2} t}\right)\right]
$$

where $P_{t}=$ TCA-precipitable counts at time $t$ after incubation; $P_{o}=$ TCA-precipitable counts at $t=0 ; k_{1}=$ velocity constant for degradation of the original material; $k_{2}=$ velocity constant for intermediary product degradation; $\alpha=$ fraction of intermediate products that is TCA-precipitable.

To facilitate curve fitting, the above equation was programmed on a Donner analog computer, ${ }^{1}$ and the constants were adjusted to provide optimal correlation with the experimental data. The constants obtained are $k_{1}=0.230$ ( $\mathrm{t}_{1}=3$ minutes); $k_{2}=0.004$ ( $\mathrm{t}_{1}=173$ minutes) $; \alpha=0.393$.

It is probable, however, that at zero time a fraction of the TCA-precipitable material in the homogenate was already present as the breakdown product of insulin- $\mathrm{I}^{131}$, in which case the true velocity constant $\left(k_{1}\right)$ for the degradation of the original insulin- $\mathrm{I}^{131}$ would be even higher. This would agree with the reported rate of degradation of small amounts of insulin $\mathrm{I}^{131}$ added in vitro to placental extracts (10).

Reduced gluthathione (GSH) has been previously shown to degrade insulin- $\mathrm{I}^{131}$ in vitro by rupture of disulfide linkages and to accelerate the breakdown of insulin when added to liver extracts (22. 23). Figure 4 demonstrates that, after the injection of insulin- $\mathrm{I}^{131}$ to the mother, placental homogenates degrade the bound, labeled TCAprecipitable material faster when GSH is added to the system. The experiments were carried out by the techniques described earlier for placental homogenates. Plasma was removed by washing the placental slices for 40 minutes at $0^{\circ} \mathrm{C}$ prior to cold homogenization. Two-ml aliquots of homogenate were incubated at $37.5^{\circ} \mathrm{C}$ after the addition of either $0.2 \mathrm{ml}$ of saline or the same volume of GSH solution. The final concentrations of GSH in the homogenate were $1.5 \mathrm{mM}$ and $7.5 \mathrm{mM}$ in different experiments. At the time intervals indicated, paired tubes were precipitated with cold TCA. Values are expressed as the percentage of

\footnotetext{
${ }^{1}$ Courtesy, Military College of South Carolina.
} 


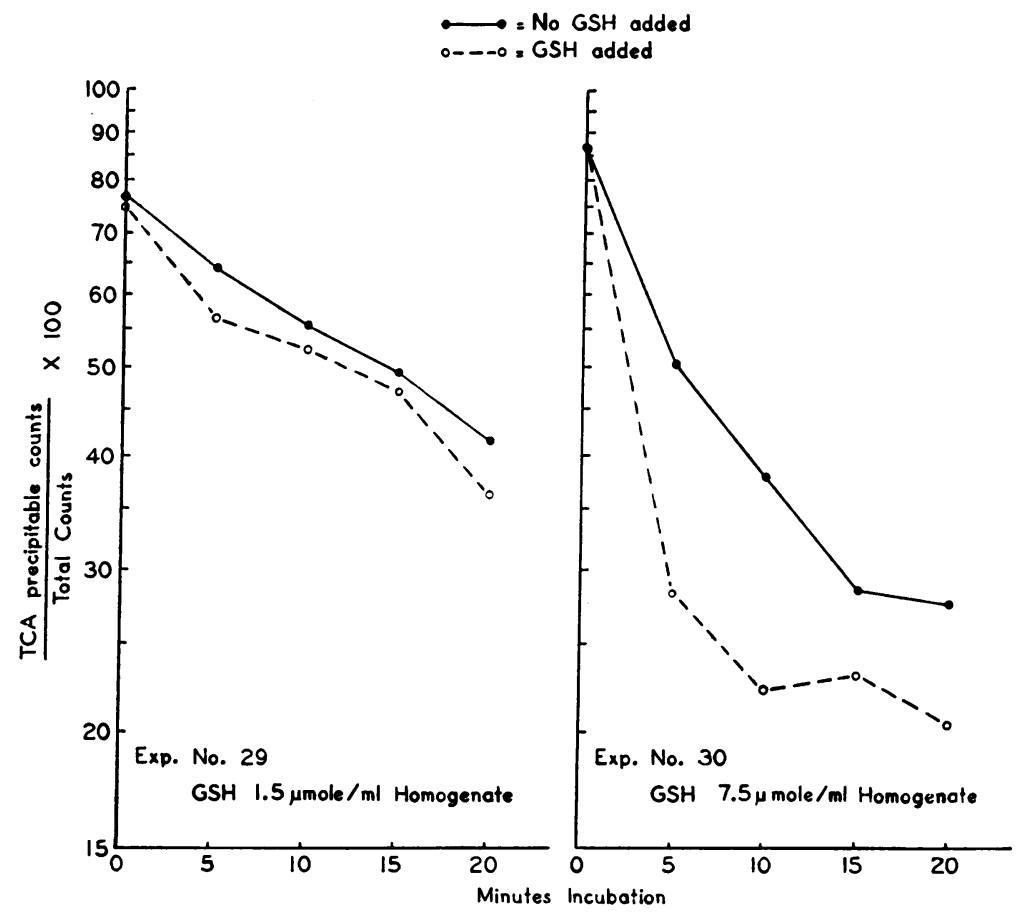

Fig. 4. The effect of reduced glutathione (GSH) on the degradaTION OF THE BOUND LABELED MATERIAL BY PLACENTAL hOMOGENATES. Insulin$I^{181}$ injected 27 minutes (experiment 29) or 7 minutes (experiment 30 ) prior to delivery. Placentas were frozen at delivery and placental slices washed for 40 minutes at $0^{\circ} \mathrm{C}$ prior to cold homogenization with an equal volume of bicarbonate buffer (11) containing glucose; $0.2 \mathrm{ml}$ of saline or GSH solution was added in the cold to $2-\mathrm{ml}$ aliquots of homogenate. After incubation at $37.5^{\circ} \mathrm{C}$ paired samples were precipitated with TCA.

the total radioactivity precipitable with TCA. It will be observed that when no GSH was added to the system, the homogenate of the placenta obtained 7 minutes after the injection of insulin- ${ }^{131}$ degraded the bound labeled material faster than did the placenta obtained 27 minutes after the insulin- $\mathrm{I}^{131}$ injection. This probably indicates that shortly after the injection of insulin- $\mathrm{I}^{131}$ a larger fraction of the bound radioactivity consists of unaltered insulin- ${ }^{131}$.

In both experiments the radioactivity appeared faster in the TCA-soluble fraction of the homogenate when GSH was added to the system. Increasing the concentration of added GSH increased the rate of degradation of the TCA-precipitable material. These experiments indicate that when insulin- $\mathrm{I}^{131}$ is administered to the mother, the labeled material which is bound and subsequently degraded by the placenta possesses intact disulfide linkages at the time of binding.

\section{DISCUSSION}

The primary objective of this study was to determine whether the human placenta is permeable to insulin at term. The use of insulin- $\mathrm{I}^{131}$ as a tracer seems justified in view of mounting evidence indicating that the biological potency and metabolic fate of the currently available, carefully labeled insulin- $\mathrm{I}^{131}$ is identical with native insulin $(21,24,25)$. However, the reservation should be made during application in vivo that insulin- $\mathrm{I}^{\mathbf{1 8 1}}$ represents a heterologous protein, subjected to minor but significant modifications in the process of labeling (25).

The dose of insulin- $\mathrm{I}^{131}$ administered to each patient $(0.5 \mathrm{U})$ should not have altered equilibrium conditions or saturated the transport system of the placenta, since this dose has little effect on the blood sugar of normal, fasting adults (26) and is much less than the amount of insulin se- 
creted by the pancreas in response to a glucose load (27).

The short biological half-life of insulin (35 minutes in nonpregnant women) (14) and the small amounts of radioactivity that can be safely administered to humans imposed serious limitations upon the time period during which observations were feasible and precluded characterization of the small amounts of TCA-precipitable radioactivity that appeared in fetal plasma after the injection of insulin- $\mathrm{I}^{131}$ to the mother. However, since at all time intervals studied (up to $65 \mathrm{~min}$ utes after single injections and 4 hours after the start of slow, continuous infusions) the TCAprecipitable counts in fetal plasma remained very low, it can be concluded that either the placenta represents an effective barrier to the transport of insulin- $\mathrm{I}^{131}$ from mother to fetus or the fetus metabolizes insulin- $\mathrm{I}^{131}$ at a rate greatly exceeding the maternal rate. The latter hypothesis seems unlikely, since no accumulation of TCA-soluble breakdown products of insulin- $\mathrm{I}^{131}$ could be detected in fetal plasma; the liver of the newborn contained the same amount of radioactivity as the periphery; and finally, since the circulating degradation products of insulin- $\mathrm{I}^{131}$ are partially precipitable with TCA $(14,25)$, a rise in TCA-precipitable counts in fetal plasma should have been detected with time if significant amounts of insulin- $\mathrm{I}^{131}$ had crossed the placental barrier and had been rapidly metabolized by the fetus.

The time required for complete equilibration of insulin- $\mathrm{I}^{131}$ in the "apparent insulin space" varies between 30 and 40 minutes in humans (14). Because at this time only minute amounts of TCAprecipitable radioactivity appeared in fetal plasma, it is apparent that the fetal circulation is not part of the maternal insulin- $\mathrm{I}^{131}$ space.

It is concluded that the human placenta at term is relatively impermeable to insulin- $\mathrm{I}^{131}$. Although the possibility of slow transport cannot be excluded by the present experiments, it seems unlikely that biologically significant amounts of insulin could thus be transported from mother to fetus, owing to the rapid systemic degradation of the hormone by the mother.

Iodide $^{131}$ equilibrated rapidly across the placenta, equilibration being 50 per cent at 15 minutes and 90 per cent 80 minutes after a single in- jection of $\mathrm{NaI}^{131}$ to the mother. At equilibrium the concentrations of inorganic $\mathrm{I}^{131}$ in maternal and fetal plasma were equal. When $\mathrm{NaI}^{131}$ is administered to pregnant rodents, the concentration of $\mathrm{I}^{131}$ in fetal plasma exceeds significantly that in maternal plasma (28). Because the mothers in the present experiments were premedicated with a saturated solution of potassium iodide, this iodide-concentrating mechanism, if present in the human, may have been blocked.

The reported experiments indicate that the placenta represents not merely a physical barrier to the transport of insulin- $\mathrm{I}^{131}$ but that it actively traps and degrades the hormone. The following evidence suggests that the radioactive material trapped by the placenta in vivo was indeed insulin$\mathrm{I}^{131}$ and not its circulating breakdown products: The radioactive material accumulated in the placenta within minutes after the injection, when the levels of circulating breakdown products were still low (14). When the placenta was obtained shortly after the injection of insulin- $\mathrm{I}^{131}$ the observed rate of degradation of the bound labeled material was similar to that of small quantities of insulin- $\mathrm{I}^{131}$ added to placental extracts (10). The addition of reduced glutathione to placental homogenates accelerated the degradation of the bound labeled material, indicating that this material possessed disulfide linkages $(22,23)$. The ability of the placenta to bind and metabolize insulin is shared by many tissues, the quantitatively most important being kidney, liver, and muscle $(17,19,21-24,29-31)$.

There is growing agreement among clinicians that the insulin requirements of diabetics increase during pregnancy. (For review of the literature see Ref. 10.) The response to exogenous insulin (32) and to tolbutamide (33) is diminished even in nondiabetics, especially during the latter part of gestation. Pregnant rats degrade 35 per cent more exogenous insulin per minute than do their nonpregnant litter mates (25). The present experiments support the interpretation that the removal and degradation of circulating insulin by the placenta can significantly alter the total insulin demands of the organism during pregnancy $(10,25)$.

The reported studies do not permit a quantitative estimate of the amount of insulin degraded by 
the placenta at term. Only 4 per cent of the total injected radioactivity could be accounted for in the placenta 13 to 28 minutes after the injection of insulin- $\mathrm{I}^{131}$. However, the degradation studies indicate that the turnover rate of the bound labeled material is very rapid. Although insulin- $\mathrm{I}^{131}$ is initially firmly bound to the placenta, a significant fraction of the degradation products must be rapidly removed by the circulation. This is illustrated by the finding that significantly more radioactivity could be removed from placental slices by washing at $37^{\circ}$ than at $0^{\circ} \mathrm{C}$.

Perfusion studies indicate that vascular delivery may be one of the major determinants of insulin removal by tissues (19). The present studies were carried out after the initiation of labor and within 1 hour of delivery, when the perfusion of the placenta was evidently not optimal. Thus it is possible that under "physiological" circumstances a larger fraction of the injected radioactivity could be accounted for in the placenta. However, in 21-day-pregnant rats only 2 per cent of the injected radioactivity could be accounted for in the placenta at autopsy, probably owing to rapid vascular removal of the degradation products of insulin- $\mathrm{I}^{131}$ from the placenta (25).

Since the early work of Stadie, Haugaard and Vaughan, it has been generally accepted that the firm binding of insulin to the receptor tissue is a prerequisite for its biological action (29). They demonstrated a correlation between the amount of insulin bound to muscle and the magnitude of the resulting stimulation of glucose utilization. Although the biological significance of in vitro binding of insulin by tissues has been recently challenged (11), the ability of certain tissues to bind and concentrate insulin in vivo remains well established $(17,19,21,31)$.

In the present experiments, insulin- $\mathrm{I}^{131}$ "bound" to the placenta (that is affixed to the tissue after repeated prolonged washing), was rapidly degraded during incubation at $37^{\circ} \mathrm{C}$. It has been reported that, after the injection of insulin- $\mathrm{I}^{131}$ to rats, the radioactivity which is affixed to cytostructural elements of rat liver is less available to degradation than is insulin- $\mathrm{I}^{131}$ added to homogenates in vitro (31). Although this may indicate that tissue binding protects insulin from degradation, it is also possible that an important fraction of the TCA-precipitable radioactivity bound to the liver consisted of intermediary degradation products of the hormone.

Many tissues that can bind and degrade insulin have not yet been shown to respond to the hormone $(30,34)$. Even in the case of the kidney and the liver, the two major sites of insulin removal and degradation, the direct metabolic influence of the hormone upon these tissues is still controversial (34). The demonstrated ability of the placenta to bind and degrade insulin in vivo may serve to protect the fetus from the postprandial fluctuations of circulating maternal insulin levels (27). However, it may also reflect the metabolic regulation of the placenta by the hormone. Insulin increases glucose utilization and glycogen synthesis of human placental slices in vitro (35). Placental slices from diabetic rats utilize less glucose and convert less glucose to $\mathrm{CO}_{2}$ and fatty acids than do controls (36).

The high fetal wastage and the well known metabolic and developmental disturbances of infants born to diabetic mothers have not been fully explained, although maternal hyperglycemia, ketoacidosis and atherosclerosis are important factors $(37,38)$. If the placenta per se needs insulin for its optimal function and development, the "insulindeficient placenta" may be detrimental to the developing fetus.

\section{SUMMARY}

1. The transfer of insulin- $\mathrm{I}^{131}$, iodide ${ }^{131}$, and radioiodinated serum albumin across the placental barrier was studied in 28 patients. Tracer amounts of labeled material were injected or infused into the mother 7 minutes to 4 hours prior to delivery.

2. The trichloroacetic-soluble breakdown products of insulin- $\mathrm{I}^{131}$ as well as iodide ${ }^{131}$ equilibrated rapidly between mother and fetus, while only minute amounts of labeled trichloroacetic-precipitable material were found in fetal plasma after the administration of insulin- ${ }^{131}$.

3. Significant amounts of labeled material were trapped by the placenta after the injection of insulin- $\mathrm{I}^{131}$, but not after the injection of iodide ${ }^{131}$ or radioiodinated serum albumin.

4. The bound labeled material present in the placenta after the injection of insulin- $\mathrm{I}^{131}$ was 
rapidly degraded when placental slices or homogenates were incubated at $37.5^{\circ} \mathrm{C}$. The addition of reduced glutathione to the system increased the rate of degradation.

5. It is concluded that the placental barrier at term is relatively impermeable to insulin and that the human placenta traps and degrades significant amounts of insulin in vivo.

\section{ACKNOWLEDGMENT}

The excellent technical assistance of Miss Louise Harrington is gratefully acknowledged. The authors are indebted to Dr. Donald J. Wright for his generous assistance in the mathematical analysis of the data, and to Dr. Lawrence L. Hester, Professor of Obstetrics and Gynecology at the Medical College of South Carolina, and his staff of interns and residents whose constant cooperation made this study possible.

\section{REFERENCES}

1. Carlson, A. J., and Drennan, F. M. The control of pancreatic"diabetes" in pregnaney by the passage. of the internal secretion of the pancreas of the fetus to the blood of the mother. Amer. J. Physiol. 1911, 28, 39.

2. Carlson, A. J., Orr, J. S., and Jones, W. S. The absence of sugar in the urine after pancreatectomy in pregnant bitches near term. J. biol. Chem. 1914, $17,19$.

3. Markowitz, J., and Soskin, S. Pancreatic diabetes and pregnancy. Amer. J. Physiol. 1927, 79, 553.

4. Allen, F. M. Experimental studies in diabetes. Series II. The internal pancreatic function in relation to body mass and metabolism. 9. The influence of pregnancy upon experimental diabetes. Amer. J. Physiol. 1921, 54, 451.

5. Pack, G. T., and Barber, D. The placental transmission of insulin from fetus to mother (abstract). Amer. J. Physiol. 1929, 90, 466.

6. Snyder, F. F., and Hoskins, F. M. The placental transmission of adrenalin, insulin and pituitrin (abstract). Anat. Rec. 1927, 35, 23.

7. Davies, J., and Lacy, P. E. Observations on the failure of insulin to pass from the fetus to the mother in the rabbit. Amer. J. Obstet. Gynec. 1957, 74, 514.

8. Knobil, E., and Josimovich, J. B. Placental transfer of thyrotropic hormone, thyroxine, triiodothyronine and insulin in the rat. Ann. N. Y. Acad. Sci. 1959, 75, 895.

9. Goodner, C. J., and Freinkel, N. Carbohydrate metabolism in pregnancy: The degradation of insulin by extracts of maternal and fetal structures in the pregnant rat. Endocrinology 1959, 65, 957.

10. Freinkel, N., and Goodner, C. J. Carbohydrate metabolism in pregnancy. I. The metabolism of in- sulin by human placental tissue. J. clin. Invest. 1960, 39, 116.

11. Newerly, K., and Berson, S. A. Lack of specificity of insulin- $\mathrm{I}^{\text {131 }}$-binding by isolated rat diaphragm. Proc. Soc. exp. Biol. (N. Y.) 1957, 94, 751.

12. Bouman, J., and Homan, J. D. H. A method for the determination of insulin by paper chromatography. Biochim biophys. Acta 1958, 29, 417.

13. Bird, R., and Farran, H. E. A sensitive method for the detection of iodinated compounds in human plasma and its applications in the study of thyrotoxicosis. J. clin. Endocr. 1960, 20, 81.

14. Berson, S. A., Yalow, R. S., Bauman, A., Rothschild, M. A., and Newerly, K. Insulin- ${ }^{181}$ metabolism in human subjects: Demonstration of insulin binding globulin in the circulation of insulin treated subjects. J. clin. Invest. 1956, 35, 170.

15. Gey, G. O., and Gey, M. K. The maintenance of human normal cells and tumor cells in continuous culture. I. Preliminary report: Cultivation of mesoblastic tumors and normal tissue and notes on methods of cultivation. Amer. J. Cancer 1936, 27, 45.

16. Fisher, R. A., and Yates, F. Statistical Tables for Biological, Agricultural and Medical Research, 2nd ed. London, Oliver \& Boyd, 1943.

17. Elgee, N. J., Williams, R. H., and Lee, N. D. Distribution and degradation studies with insulin- $\mathrm{I}^{131}$. J. clin. Invest. 1954, 33, 1252.

18. Allgood, J. W. The renal clearance of $\mathrm{I}^{131}$ during the infusion of $\mathrm{NaI}^{131}$ and insulin- $\mathrm{I}^{131}$. Diabetes 1961, 10, 7.

19. Madison, L. L., Combes, B., Unger, R. H., and Kaplan, N. The relationship between the mechanism of action of the sulfonylureas and the secretion of insulin into the portal circulation. Ann. N. Y. Acad. Sci. 1959, 74, 548.

20. Riggs, D. S. Quantitative aspects of iodine metabolism in man. Pharmacol. Rev. 1952, 4, 284.

21. Lee, N. D. The specificity of the interaction of insulin- $\mathrm{I}^{181}$ with tissue. Endocrinology 1959, 65, 347.

22. Narahara, H. T., Tomizawa, H. H., and Williams, R. H. Sulfhydryl factors in degradation of insulin- $\mathrm{I}^{131}$ by liver extracts. Proc. Soc. exp. Biol. (N.Y.) 1956, 92, 718.

23. Narahara, H. T., and Williams, R. H. Reduction of insulin by extracts of rat liver. J. biol. Chem. 1959, 234, 71.

24. Wick, A. N., and Drury, D. R. Effects of superimposed native insulin on disposal of iodoinsulin in the body. Proc. Soc. exp. Biol. (N. Y.) 1958, 97, 514.

25. Goodner, C. J., and Freinkel, N. Carbohydrate metabolism in pregnancy: The turnover of $\mathrm{I}^{181}$ insulin in the pregnant rat. Endocrinology 1960, 67, 862.

26. Bell, D. M., and Burns, T. Effect on femoral A-V glucose difference of insulin injected into an ante- 
cubital vein and into a femoral artery. J. clin. Invest. 1952, 31, 717.

27. Yalow, R. S., and Berson, S. A. Immunoassay of endogenous plasma insulin in man. J. clin. Invest. 1960, 39, 1157.

28. Logothetopoulos, J., and Scott, R. F. Active iodide transport across the placenta of the guinea-pig, rabbit and rat. J. Physiol. (Lond.) 1956, 132, 365.

29. Stadie, W. C., Haugaard, N., and Vaughan, M. Studies of insulin binding with isotopically labeled insulin. J. biol. Chem. 1952, 199, 729.

30. Williams, R. H., Hay, J. S., and Tjaden, M. B. Degradation of insulin- $\mathrm{I}^{131}$ and glucagon- $\mathrm{I}^{131}$ and factors influencing it. Ann. N. Y. Acad. Sci. 1959, $74,513$.

31. Lee, N. D., and Wiseman, R., Jr. The significance of the binding of insulin- $\mathrm{I}^{131}$ to cytostructural elements of rat liver. Endocrinology 1959, 65, 442.
32. Burt, R. L. Peripheral utilization of glucose in pregnancy. III. Insulin tolerance. Obstet. and Gynec. 1956, 7, 658.

33. Kaplan, N. M. Tolbutamide tolerance test in carbohydrate metabolism evaluation. Arch. intern. Med. 1961, 107, 212.

34. Renold, A. E., and Winegrad, A. I. Insulin action; effects on individual tissues in Diabetes, R. H. Williams, Ed. New York, Hoeber, 1960, p. 129.

35. Villee, C. A. The metabolism of human placenta in vitro. J. biol. Chem. 1953, 205, 113.

36. Hagerman, D. D., and Wellington, F. M. Metabolic studies of tissues from pregnant, alloxandiabetic rats. Fed. Proc. 1960, 19, 165.

37. Duncan, G. G. Pregnancy complicating diabetes in Diseases of Metabolism, G. G. Duncan, Ed. Philadelphia, Saunders, 1959, p. 904.

38. Garnet, J. D. Pregnancy complicated by diabetes. Amer. J. Obstet. Gynec. 1960, 79, 14. 